\title{
A comparative study to see the effectiveness of Pap smear, visual inspection with 3-5\% acetic acid and its confirmation by cervical biopsy
}

\author{
Mili D. Choudhury ${ }^{1 *}$, Sivaji S. Ghose ${ }^{2}$, Milind Y. Dharmamer ${ }^{3}$
}

\begin{abstract}
${ }^{1}$ Department of Obstetrics and Gynecology, Naval Hospital Powai, Mumbai, Maharashtra, India
${ }^{2}$ Department of Surgery, Naval Hospital Powai, Mumbai, Maharashtra, India

${ }^{3}$ Department of Anaesthesia, Naval Hospital Powai, Mumbai, Maharashtra, India
\end{abstract}

Received: 30 November 2019

Revised: 27 December 2019

Accepted: 02 January 2020

\section{*Correspondence:}

Dr. Sivaji S. Ghose,

E-mail: sharkdoctor007@gmail.com

Copyright: (C) the author(s), publisher and licensee Medip Academy. This is an open-access article distributed under the terms of the Creative Commons Attribution Non-Commercial License, which permits unrestricted non-commercial use, distribution, and reproduction in any medium, provided the original work is properly cited.

\section{ABSTRACT}

Background: Cancer of the cervix is a leading cause of morbidity and mortality among women worldwide. The present study was undertaken to compare the effectiveness of Pap smear and visual inspection with 3-5\% acetic acid (VIA) in screening carcinoma cervix followed by its confirmation by cervical biopsy.

Methods: A total of 100 patients with abnormal looking cervices or symptomatic patients having age beyond 30 years, attending the obstetrics and gynaecology OPD at Naval Hospital Powai, Mumbai from $31^{\text {st }}$ December 2015 to $31^{\text {st }}$ December 2017 were selected for the study. Pap smear and VIA was done on consecutive days. In positive cases cervical biopsy were done to confirm the result.

Results: The sensitivity of VIA was $100 \%$ but at the same time specificity was $41 \%$ there will be unnecessary investigation and biopsy in false positive cases. The sensitivity of cytology was $75 \%$ and specificity was $97 \%$. Not a single case was missed by Pap smear only one case of severe dysplasia on cytology had squamous cell carcinoma on HPE which was done after 90 days because of delay in patients follow up.

Conclusions: Both the Pap smears and VIA is very effective screening tool for cervical cancer and histopathological examination remains the mainstay. But VIA is very cost effective and easy procedure, though it gives false positive reports but is not going to miss any case, rather leads to over diagnosis of the cases with cervicitis and hence treatment starts early and thus the progress of disease can be slowed down or even stopped.

Keywords: Acetic acid, Biopsy, Cancer, Cervix, Dysplasia, Mainstay, Pap smear, Squamous cell carcinoma

\section{INTRODUCTION}

Worldwide cancer accounts for $9 \%$ of deaths. In developed countries cancer is the leading cause of death next to cardiovascular disease but in developing countries it ranks fourth as a cause of death. ${ }^{1,2}$ Approximately half a million women are diagnosed with cervical cancer each year making it the second most common malignancy in women globally. ${ }^{3,4}$ In India among all type of genital cancer, carcinoma cervix accounts for $80 \%$, ovary $10 \%$, and uterine body $4-5 \% .^{5}$ Carcinoma cervix does not arise de novo but follows a spectrum of premalignant epithelial abnormalities in the form of dysplasia or CIS. Since cervix is a readily accessible organ for examination, it is considered as an unique malignancy that can be prevented. ${ }^{6}$ In India cervical cancer is the most common women related cancer killing one woman every 8 minutes according to National Cancer registry program by Indian Council of Medical Research (ICMR) in the year 2007, about $1,32,082$ are affected by cancer cervix every year in 
India and 74,118 die of the disease. ${ }^{7}$ In view of natural history of disease cervical cytology screening continues to be the main stay in diagnosis of cervical cancer. ${ }^{8}$

In developing countries due to lack of resources, primary health care, literacy and lack of follow up the screening programmes are only institution based and caters a limited group of population. Hence there is a need to look at alternate strategies for mass screening. Practically the procedure should be easy, simple, effective, inexpensive, less time consuming and should be acceptable to the female population. ${ }^{9}$ In the present era in addition to exfoliative cytology, researchers are finding many alternative screening procedures like visual inspection, visual inspection with acetic acid, schillers test, cervicoscopy, gynoscopy, colposcopy, HPV typing etc. In the present study only symptomatic patients coming to OPD and abnormal looking cervices were chosen as study group. A comparison was made between findings of exfoliative cytology and visual inspection with acetic acid in order to see the effectiveness of procedure and in positive cases cervical biopsy being done in order to find the sensitivity and specificity of all procedures.

\section{METHODS}

The present study was carried out in the department of obstetrics and gynaecology, at Naval Hospital Powai, Mumbai during a period of 2 years from $31^{\text {st }}$ December 2015 to $31^{\text {st }}$ December 2017. A total of 100 women with abnormal looking cervices or symptomatic patients (e.g. vaginal discharge, itching vulva, postmenopausal bleeding etc.) attending obstetrics and gynaecology OPD and family welfare centre of NH Powai were chosen as the cases for the study. The inclusion criteria were women between 30 to 75 years of age, irrespective of parity, parity of one or more irrespective of age, women having cervical erosion, cervicitis, hypertrophied cervix, cervical polyp, uterine prolapse with ulceration, vaginal discharge, postmenopausal, bleeding and post coital bleeding were considered as unhealthy cervices, women using contraceptives. Clinically diagnosed advance cases and cancer cervix were excluded from the study.

A detailed clinical history including age, age of marriage, first child birth, number of children, socioeconomic status, number of partners and a proforma was made for each of the hundred cases. Detailed history of their husband, socioeconomic status, coital practices, obstetrics history, menstrual history, present complaints was noted. Personal history, past history, general, systemic, local, bimanual and rectal examination records were kept. These ladies were subjected to routine blood, urine examination, VDRL, HIV < iii random blood sugar along with papnicolaou's stain, VIA with $3-5 \%$ acetic acid and finally histopathoplogical examination. All the cases were subjected to exfoliative cytology i.e., pap smear, without waiting for its report they were all subjected to staining with $3-5 \%$ acetic acid within two or three days. Then the positive cases were subjected to histopathological examination. The reports of Pap smear, VIA and cervical biopsy were compared and were followed up for subsequent management. The findings were then compared to find the effectiveness of the screening procedures. All the data were presented in number of patients.

\section{RESULTS}

Out of 100 patients enrolled in the study, 3 cases had Mild dysplasia, 1 case had severe dysplasia, 1 case had carcinoma in situ (CIS) and 31 patients had chronic inflammation smear and 64 had normal smear. However, we found 58 cases with acetowhite area, 1 case with white gland opening and 1 case with polyp turning white arising from the anterior lip of cervix and 40 cases without any change on application of $3-5 \%$ acetic acid and had normal findings. Histopathological report shows 1 case each of moderate dysplasia, carcinoma in situ and squamous cell carcinoma and all the observations are shown in (Table 1).

Table 1: Result of Papnicolaou's stain, VIA with 3-5\% acetic acid and histopathoplogical examination among the study group.

\begin{tabular}{|ll|}
\hline PAP Smear & No. of cases \\
\hline Mild dysplasia & 03 \\
\hline Moderate dysplasia & 00 \\
\hline Severe dysplasia & 01 \\
\hline Carcinoma in Situ & 01 \\
\hline inflammation & 31 \\
\hline Normal findings & 64 \\
\hline VIA with 3-5\% acetic acid & \\
\hline Leukoplakia & 00 \\
\hline Aceto white area & 58 \\
\hline White gland opening & 01 \\
\hline Mosaic punctate & 00 \\
\hline Miscellaneous & 01 (polyp) \\
\hline Normal findings & 40 \\
\hline HPE report & \\
\hline Moderate dysplasia & 01 \\
\hline Severe dysplasia & 00 \\
\hline Carcinoma in Situ & 01 \\
\hline Squamous cell carcinoma & 01 \\
\hline Inflammatory & 18 \\
\hline Normal findings & 79 \\
\hline
\end{tabular}

Summarising the result from the (Figure 1), we find cytology more or less correlating with HPE report. On cytology 03 cases had mild dysplasia out of which only 01 case had moderate dysplasia on HPE and other 02 cases were inflammatory. 01 case had severe dysplasia on cytology which on HPE showed squamous cell carcinoma where time period (since the time on which biopsy was taken about 90 days later from the date when Pap smear was done) may be one of the cause for the mismatching of the reports. Rest all the cases tallied. 


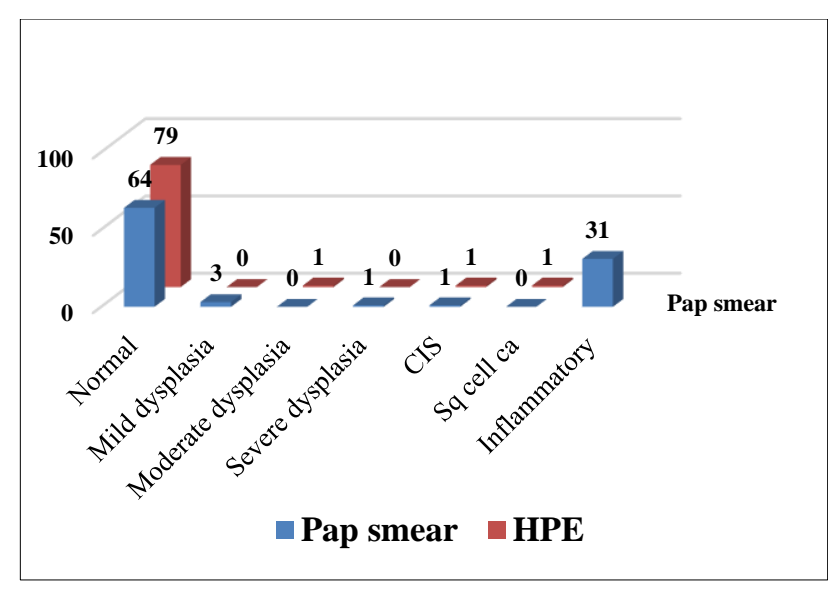

Figure 1: Comparative results between Pap smear and histopathology.

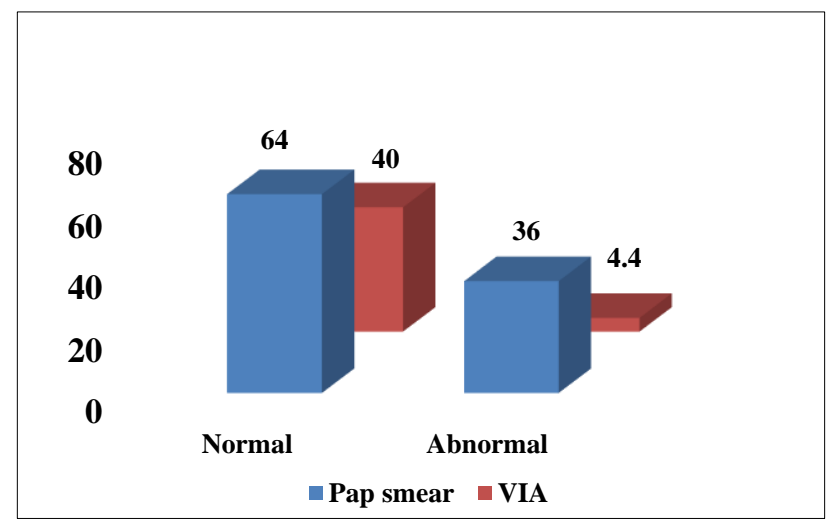

Figure 2: Correlation of VIA report with cytology.

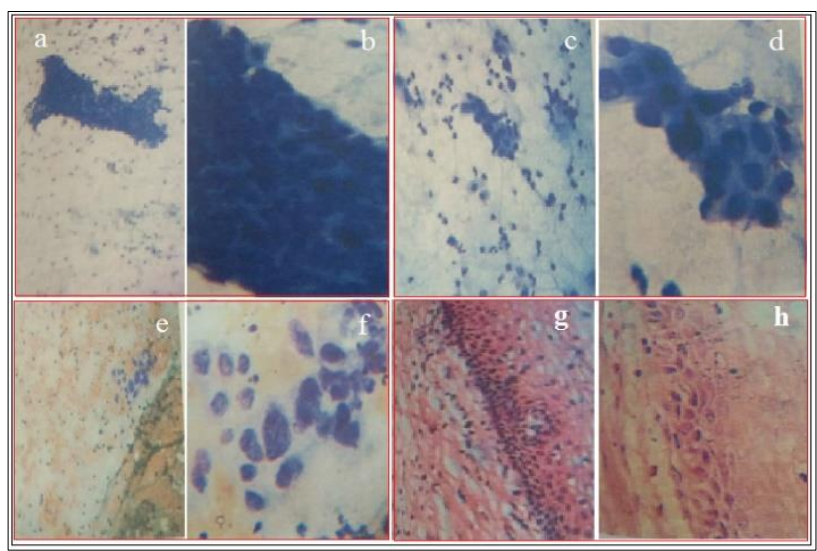

Figure 3: Pap smear - a) low and b) high power mild dysplasia, c) low and d) high power moderate dysplasia, e) low and f) high power severe dysplasia, HPE g) low and high-power moderate dysplasia.

Comparing the VIA report with cytology and HPE it is found that it has not missed a single positive case but at the same time it is positive in many inflammatory and normal cases too, (Figure 2).
The relationship between Pap smear, VIA and HPE Report being the standard for comparison is shown in (Table 2).

Table 2: Relationship between Pap smear, VIA and HPE report.

\begin{tabular}{|llll|}
\hline Particulars & PAP & VIA & $\begin{array}{c}\text { HPE } \\
\text { report }\end{array}$ \\
\hline Mild dysplasia & 3 & 3 (acetowhite) & - \\
\hline Moderate dysplasia & - & - & 1 \\
\hline $\begin{array}{l}\text { Severe dysplasia } \\
\text { Carcinoma in situ }\end{array}$ & 1 & 1 (white gland) & 0 \\
\hline $\begin{array}{l}\text { Squamous cell } \\
\text { carcinoma }\end{array}$ & - & 1 (acetowhite) & 1 \\
\hline Inflammation & 31 & 54 (acetowhite) & 18 \\
\hline Normal & 64 & 40 & 79 \\
\hline
\end{tabular}

\section{DISCUSSION}

Carcinoma cervix is the second most common cancer in developing countries like India it is most important cancer among the women in past two decades by now it is known that the accessibility of uterine cervix, propensity of cells to exfoliate from precancerous lesion, the evidence from pathological studies of existence of histological changes from mild atypia through premalignancy to the frank malignancy, the apparently prolonged natural history the long premalignant phase and the ability for detecting changes using potential for control of cervical cancer. ${ }^{10-12}$ It is assured that cervical intraepithelial neoplasia (CIN) acts as a premalignant disease and progress slowly over a period of 15-20 years to invasive cancer. Immense attention has been paid to natural history of cancer cervix and it has been proved beyond doubt that during the course of development of the disease there is sufficiently large period in which it is absolutely curable. Much of the recent increase in cancer incidence can be explained by known risk factors and improved detection rate and this justifies the importance of earliest possible diagnosis in premalignant and preclinical stages.

Keeping in mind the present study was carried out to compare the effectiveness of various screening procedures in 100 symptomatic women of age 30 years or more attending the gynaecological OPD of NH Powai during the period of 2015-2017.

Amongst various modalities for control of cancer cervix, screening to diagnose preinvasive lesions remain the only means to curb the disease. Screening of cancer cervix causes a dramatic reduction in mortality (50 to $70 \%) .{ }^{13,14}$ The appropriateness of a screening test depends not only on its accuracy, as measured mainly by sensitivity and specificity but also on its simplicity and safety. ${ }^{15}$ Alternative methods for cervical cancer screening have been sought. One method, direct visualization with acetic acid has gained popularity and proven itself in many 
clinical trials as an adequate alternative to PAP smears in developing countries. ${ }^{16}$

Naked eye visual inspection of the cervix after application of 3 to $5 \%$ acetic acid causes a reversible coagulation or precipitation of the cellular proteins. Areas with dysplasia or invasive cancer have large number of undifferentiated cells in the epithelium and hence undergo maximal coagulation because of higher content of nuclear protein and prevent light from passing through the epithelium, hence these areas appear acetowhite (Figure 4).

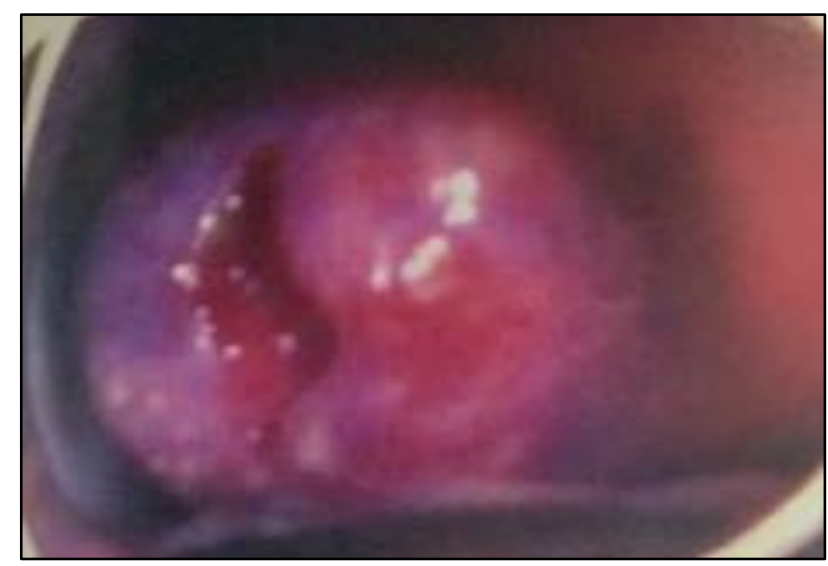

Figure 4: Visual inspection after the application of acetic acid (VIA) - positive lesion.

Most studies compared VIA with PAP, looking at sensitivities and specificities of both, while comparing them to colposcopy with biopsy as the gold standard with varying results. Comparing with the previous study we find that our result of cytology i.e. sensitivity was $75 \%$ where as in previous study it was $62 \% .{ }^{17}$ The specificity was $97 \%$ in our study and $89 \%$ in previous study. ${ }^{17}$ The reason for such a high sensitivity may be due to smear collection and preparation of the slide and its interpretation. Consul, et al reported the sensitivity of Pap smear was $84.20 \%$ and the specificity was $62.10 \% .^{18}$

The sensitivity of VIA in current study was $100 \%$ and specificity was $41 \%$. Thus, VIA showed higher sensitivity compared to Pap smear, whereas VIA had lower specificity compared to Pap smear. In Shankarnarayan et al, study the sensitivity and specificity of VIA being $95.8 \%$ and $68 \% .^{17}$ Consul, et al found sensitivity of VIA was $84.20 \%$ and specificity of $55.20 \% .{ }^{18}$ The result of present study more or less correlates with the previous study and the reason for $100 \%$ sensitivity may be due to the fact that $54 \%$ of patients have chronic cervicitis and hence have positive results falsely. Because of the high number of falsepositive cases and low specificity of VIA, the usefulness of this procedure is limited. But, due to the high sensitivity of VIA, it is still used as primary screening in some developing countries for early detection of cervical carcinoma. ${ }^{18}$
Among 100 total cases, 61 cases were from Hindu religion and 38 were Muslim and 1 case was from other religion. The incidence of abnormal smear was more in Hindu religion. CIN were present more in Hindu religion i.e. 5 out of total 8 positive cases and only 3 cases in Muslim community. This finding correlated with the previous studies. ${ }^{19,20}$ The dysplastic lesions were more common in 30-39 years age group. The grade of lesion increases as the age increases. Similar results were obtained by Upreti and Rohtage. ${ }^{21}$ The average age for mild to moderate dysplasia was 32.5 years (37 patients) and average age for severe dysplasia was 37 years (38 cases). The mean age for CIS and invasive cancer was 38.5 years (41 cases) and 42 years (46 cases) respectively. These findings are compared with the Saraiya and Lula. ${ }^{22}$

Duration of marriage and duration of exposure to sexual intercourse has an important role in the genesis of cervical dysplasia. In present study, 8 cases were married at the age of 15 years or less and 63 cases were married between 16-20 years age group and 29 cases were married at more than 20 years of age. The development of CIN were more in 16-20 years age group of marriage i.e. 6 out of total 8 positive cases and development of CIN in 1 case each of $<15$ years and $>20$ years age group of marriage. These results are corresponded with the study done by Bhattacharyya et al. ${ }^{23}$

\section{CONCLUSION}

Both the Pap smears and VIA is very effective screening tool for cervical cancer and histopathological examination remains the mainstay but, in a resource, poor country VIA can be implemented which is very cost effective and easy procedure. Though it gives false positive reports but is not going to miss any case, rather will over diagnose the cases with inflammation and hence treatment can be started early and the progress of the disease can be slowed down or even stopped.

Funding: No funding sources Conflict of interest: None declared

Ethical approval: The study was approved by the Institutional Ethics Committee

\section{REFERENCES}

1. $\mathrm{Ma} X, \mathrm{Yu}$ H. Global burden of cancer. Yale J Biol Med. 2006;79(3-4):85-94.

2. Bray F, Ferlay J, Soerjomataram I, Siegel RL, Torre LA, Jemal A. Global cancer statistics 2018: GLOBOCAN estimates of incidence and mortality worldwide for 36 cancers in 185 countries. A Cancer J Clin. 2018;68(6):394-424.

3. Ginsburg O, Bray F, Coleman MP, Vanderpuye V, Eniu A, Kotha SR, et al. The global burden of women's cancers: a grand challenge in global health. Lancet. 2017;389(10071):847-60. 
4. Hailemariam T, Yohannes B, Aschenaki H, Mamaye E, Orkaido G, Seta M. Prevalence of cervical cancer and associated risk factors among women attending cervical cancer screening and diagnosis center at Yirgalem General Hospital, Southern Ethiopia. J Cancer Sci Ther. 2017;9:730-5.

5. Kaarthigeyan K. Cervical cancer in India and HPV vaccination. Indian $\mathbf{J}$ Med Paediatr Oncol. 2012;33(1):7-12.

6. Christopherson WM. Dysplasia, carcinoma in situ, and microinvasive carcinoma of the uterine cervix. Hum Pathol. 1977;8(5):489-501.

7. Bobdey S, Sathwara J, Jain A, Balasubramaniam G. Burden of cervical cancer and role of screening in India. Ind J Med Paediatr Oncol. 2016;37(4):278-85.

8. Mishra GA, Pimple SA, Shastri SS. An overview of prevention and early detection of cervical cancers. Indian J Med Paediatr Oncol. 2011;32(3):125-32.

9. Das S, Mishra G, Paul S. Evaluation of cytology in unhealthy cervix. J Indian Med Asso. 1984;82:166.

10. Juneja A, Snehal A. A survey of risk factors associated with cervical cancer. Ind $\mathrm{J}$ Cancer. 2003;40:15-22.

11. Vaidya A. Comparison of PAP test among high risk and non-risk female. Kathmandu Univ Med J. 2003;1:18-3.

12. Donkoh ET, Agyemang-Yeboah F, Asmah RH, Wiredu EK. Prevalence of cervical cancer and precancerous lesions among unscreened Women in Kumasi, Ghana. Med (Baltimore). 2019;98(13):e14600.

13. Bigerne and Johanson. 1983 cancer of cervix edited by Hugh M Shinyele Ton and James W Orr. $1^{\text {st }}$ edition; 1987.

14. Boyes DA, Worth AJ. Treatment of early cervical neoplasia: definition and management of pre-clinical invasive carcinoma. Gynecol Oncol. 1981;12:31730 .

15. Arbyn M, Sankaranarayanan R, Munwongs R, Keita N, Dolo A. Pooled analysis of the accuracy of five cervical cancer screening tests assessed in eleven studies in Africa and India. Int $\mathbf{J}$ cancer 2008;123:153-60.
16. Saleh HS. Can visual inspection with acetic acid be used as an alternative to Pap smear in screening cervical cancer? Middle East Fertil Soc J. 2014;19:187-91.

17. Sankaranarayanan R, Wesley R, Somanathan T, Dhakad N, Shyamalakumary B, Amma NS, et al. Visual inspection of the uterine cervix after the application of acetic acid in the detection of cervical carcinoma and its precursors. Cancer: Interdi Int J Am Cancer Soc. 1998;83(10):2150-6.

18. Consul S, Agrawal A, Sharma H, Bansal A, Gutch M, Jain N. Comparative study of effectiveness of Pap smear versus visual inspection with acetic acid and visual inspection with Lugol's iodine for mass screening of premalignant and malignant lesion of cervix. Indian J Med Paediatr Oncol. 2012;33:161-5.

19. Pandey K, Bhagoliwal A. Cancer cervix - need for mass surveillance program specially in rural areas. $\mathbf{J}$ Obst Gynecol India. 2005;55(5):1-5.

20. Nene BM, Deshpande S, Kasturi J, Budukh AM, Dale PS, Deshpande DA, et al. Early detection of cervical cancer by visual inspection: A populationbased study in rural India. Int $\mathrm{J}$ Cancer. 1996;68(6):770-3.

21. Upreti S, Shanker R, Subramanian J, Rohtagi P. A study of cervical dysplasia and its relation with various factors. J Obst Gynecol India. 1981;834-6.

22. Saraiya U, Lula M. Evaluation of cervical lesion by combined use of cytology, colposcopy and histology. J Obst Gyne. 1984-1998.

23. Bhattacharyya AK, Nath JD, and Deka H. Comparative study between pap smear and visual inspection with acetic acid (via) in screening of CIN and early cervical cancer. J Midlife Health. 2015;6(2):53-8.

Cite this article as: Choudhury MD, Ghose SS, Dharmamer MY. A comparative study to see the effectiveness of Pap smear, visual inspection with 3$5 \%$ acetic acid and its confirmation by cervical biopsy. Int J Reprod Contracept Obstet Gynecol 2020;9:715-9. 